\begin{tabular}{|l|l|l||}
\hline \multicolumn{2}{|c|}{ PublisherInfo } \\
\hline \hline PublisherName & $:$ & BioMed Central \\
\hline \hline PublisherLocation & $:$ & London \\
\hline \hline PublisherImprintName & $:$ & BioMed Central \\
\hline \hline
\end{tabular}

\title{
Bioinformatics network cheered
}

\begin{tabular}{|l|l|l||}
\hline \multicolumn{2}{|c|}{ ArticleInfo } \\
\hline \hline ArticleID & $:$ & 4958 \\
\hline \hline ArticleDOI & $:$ & $10.1186 /$ gb-spotlight-20040216-02 \\
\hline \hline ArticleCitationID & $:$ & spotlight-20040216-02 \\
\hline \hline ArticleSequenceNumber & $:$ & 21 \\
\hline \hline ArticleCategory & $:$ & Research news \\
\hline ArticleFirstPage & $:$ & 1 \\
\hline \hline ArticleLastPage & $:$ & 3 \\
\hline \hline & & RegistrationDate : 2004-2-16 \\
\hline ArticleHistory & $:$ & OnlineDate \\
\hline \hline ArticleCopyright & $:$ & BioMed Central Ltd2004-2-16 \\
\hline \hline ArticleGrants & $:$ & \\
\hline \hline ArticleContext & $:$ & 130595511 \\
\hline \hline
\end{tabular}


Andrew Scott

Email: as@andrewscottweb.co.uk

An initiative to tackle the current fragmentation of bioinformatics research across Europe has been welcomed by scientists in both Europe and the United States.

"This helps to meet the world's scientific need for coordinated efforts in bioinformatics and computational biology," Eric Jakobsson, director of the Center for Bioinformatics and Computational Biology at the US National Institute of General Medical Sciences, told us.

The European Commission has awarded $€ 12$ million (\$15.4 million) to allow 24 bioinformatics groups in 14 countries to form a pan-European 'BioSapiens Network of Excellence in Bioinformatics'. The network will create a virtual institute for research on genome annotation, the process in which information from gene and protein databases is extracted, analyzed, and interpreted. The network will also set up a European school for training in bioinformatics.

"Research bioinformaticians developing new methods are in their own labs scattered around Europe, [and] the best methods for different aspects tend to be developed in different laboratories," Janet Thornton, director of the European Bioinformatics Institute (EBI) and coordinator of the BioSapiens network, told us. "Getting the best methods applied to particular genes is quite difficult. The idea is to bring the laboratories and methods together, so that by submitting one query over the Web, you can get back all the best information from all the laboratories at the same time."

The EBI manages some of the world's major bioinformatics databases, holding protein and DNA sequences and gene structure and expression data. "We feel it is very important to involve those data resources in the BioSapiens network," Thornton explained. A specialized software system will integrate the information in the existing databases with the research work of the network.

Although a European initiative, the output of the BioSapiens network will be freely available to researchers worldwide. This is typical of what Thornton described as an excellent system of global data sharing in this field. That sentiment is echoed by Eric Jakobsson, who said, "I regard the work of BioSapiens and of our own program of excellence [in biomedical computing] to be synergistic rather than competitive. What they do will add value to what we do, and vice versa."

European scientists who will benefit from participating in the BioSapiens network are also enthusiastic. "There is not enough support for this kind of work," Antoine Danchin of the Pasteur Institute in Paris told us. He feels the network will definitely make life easier for researchers and added: "annotation errors propagate extremely fast because they are often performed automatically... without experimental validation. One of the most important aims of BioSapiens is to reduce this percolation of errors by providing certified annotations."

"The initiative should make work easier for both experimentalists and computational biologists," Roderic Guigó, of the Research Group on Biomedical Informatics, Municipal Institute of Medical Research, in Barcelona, told us. "High-quality genome annotation is essential to convert the raw genome sequence into relevant biological knowledge." Guigó pointed out, however, that wider global coordination may also be required in the future, to address the issue of duplication of effort and 
redundancy: "At some point, when the field is mature enough... it may become necessary that some sort of loose [global] organization identifies database redundancies and suggests coordination."

The BioSapiens network should be around to participate in any tighter global cohesion that may eventually be required. "Although initially funded for 5 years, it is not meant to be a one-off project," said Janet Thornton, "but a way to bring together the labs of Europe into a network that will endure."

\section{References}

1. European Virtual Institute for Genome Annotation receives 12 million euro, European Molecular Biology Laboratory-European Bioinformatics Institute press release, January 23, 2004. [http://www.ebi.ac.uk/Information/News/pdf/pr230104.pdf]

2. Center for Bioinformatics and Computational Biology, [http://www.nigms.nih.gov/about_nigms/ cbcb.html]

3. European Virtual Institute for Genome Annotation receives $€ 12$ million Genome Biolgy 27 January, 2004, [http://genomebiology.com/researchnews/default.asp?arx_id=gb-spotlight-20040127-01]

4. European Bioinformatics Institute, [http://www.ebi.ac.uk/Information/index.html]

5. Databases at the European Bioinformatics Institute, [http://www.ebi.ac.uk/Databases/]

6. National Program of Excellence in Biomedical Computing, [http:/www.nigms.nih.gov/ biocomputing/ncbc.html]

7. Pasteur Institute, [http://www.pasteur.fr/english.html]

8. Research Group on Biomedical Informatics, Municipal Institute of Medical Research, [http://www.imim.es/grib/eng/default.htm]

This PDF file was created after publication. 